Madaule acknowledges that history is reconstructed according to the concerns of the historian. What she has tried to offer the reader is "a Lamarck seen in his own epoch through the dimensions of a perspective produced by the contemporary world" (page 175), the perspective in question being that which concerns itself with the interrelations of science and ideology. She has succeeded in demonstrating the interest of Lamarck's case for the history of science, even though there is much more of interest in Lamarck's thinking than she mentions. Given the important kinds of questions she has posed, and allowing that new perspectives will provide additional questions to ask about Lamarck's case in the future, there is every likelihood that Lamarck will continue to be of considerable interest for the history of science when his next major anniversary comes around.

R.W. Burkhardt is Associate Professor of History at the University of Illinois, Urbana, and author of The Spirit of System: Lamarck and Evolutionary Biology.

\section{Reviews of bonding}

\section{S. R. Elliott}

Electrons and Transitions. Vol. 39 of Structure and Bonding. Series editors J. D. Dunitz, J. B. Goodenough, P. Hemmerich et al. Pp.120. (Springer: Heidelberg and New York, 1980.) DM64,\$35.90.

VARIOUS themes are common to the different branches of chemistry; one such, underlying inorganic and physical chemistry in particular, is bonding and its concomitant structure. This is the title of a continuing series published by Springer, each book comprising a collection of articles. The latest addition is Vol. 39, subtitled Electrons and Transitions.

This volume contains three articles. The first, by D. W. Clack and K. D. Warren, is entitled "Metal-Ligand Bonding in 3d Sandwich Complexes". The review concentrates on the bonding between the metal and the ligand rings for various series of first-row transition metal sandwich complexes containing from three- to eightmembered carbocyclic rings. Experimental data from electronic spectra, ESR and photo-electron spectroscopy are compared with the predictions obtained principally from the authors' INDO SCF molecularorbital calculations. The article runs to 41 pages and 80 references are included.

The second article, "Ligand Polarization Model for the Spectra of Metal Complexes: The Dynamic Coupling Transition Probabilities"', is by S. F. Mason. Crystal field theory, the principal independent-systems model in which metal-ligand overlap is neglected, has been extremely successful in accounting for the character of the structure and bonding of metal complexes. Nevertheless, its shortcomings are not confined to neglect of metal-ligand electron exchange. In a firstorder independent-systems treatment, either the ligands perturb the metal ion (crystal field theory) or, in the other extreme, the metal ion perturbs the ligands (ligand polarization model). This article, of 39 pages and 82 references, considers applications of the latter approach to oscillator strengths of lanthanide and transition metal complexes, rotational strengths of chiral coordination compounds and the Faraday effect terms of achiral complexes.

The final article, by L. R. Balsenc, is "Sulfur Interaction with Metallic Surfaces and Interfaces studied by Auger Electron Spectroscopy (AES)'". This sets out to review the contribution of AES to the studies of the behaviour of sulphur on and with metallic surfaces including, amongst others, gas adsorption and desorption kinetics, surface and grain boundary segregation, corrosion, passivation and catalyst poisoning. This technique has several advantages; it is very surfacesensitive and adsorption-site positions can be deduced from the angular-dependent Auger emission from single crystal substrates, and the method's high speed of data acquisition is of great use in kinetic studies. In contrast to another commonly used technique, X-ray photo-emission spectroscopy (XPS), AES is some 20 times

\section{Floras finished and in progress}

\section{Peter D. Moore}

Flora Europaea, Vol.5. Edited by T. G. Tutin, B. H. Heywood, N. A. Burges et al. Pp. 452. (Cambridge University Press: Cambridge, UK, and New York, 1980.) $£ 37.50, \$ 85$. Flora Palaestina, Part 3. Text pp. 481, plates 757. By N. Feinbrun-Dothan. (Israel Academy of Sciences and Humanities: Jerusalem, 1979.) IL500, \$55.

"THE publication of this final volume of Flora Europaea represents a landmark in European floristics"'. So begins the preface to Vol. 5, and one can detect a flavour of relief coupled with the justifiable pride of this statement. The concept of a European flora was formed some 26 years ago and it was then hoped that it could be completed within 12 years; but the gestation period of this magnum opus proved far longer than was anticipated. This must make the final parturition a yet more satisfying occasion for the editorial committee.

The final volume is dedicated to the monocotyledons and it follows the same style adopted in previous volumes. The British botanist will find few surprises in more sensitive for sulphur detection, although XPS is far superior in the elucidation of the chemical state of the atoms by means of the 'chemical shift' since the shift is very small compared with the Auger peak width and hence easily obscured. The review is short, only 32 pages, but contains an extensive bibliography, and will be of interest in both the academic and industrial spheres.

In summary, this is a well presented book with only one niggling detail, the use of the American spelling, sulfur, although all other usage is English; the book's appeal should lie primarily with researchers in those fields represented by the articles included.

S. R. Elliott is University Demonstrator in the Department of Physical Chemistry, University of Cambridge, UK.

the arrangement and nomenclature; we are already accustomed to such transmutations as Endymion to Hyacinthoides and we could have predicted movements within the genus of marsh orchids, Datylorhiza. D. purpurella and $D$. praetermissa are now regarded as subspecies of $D$. majalis. The subspecies ericetorum of maculata is absorbed into ssp. maculata.

These, however, are trivia. The importance of this work is the establishment of an authoritative description and definition of the flora of the whole of Europe. It is the first such account ever published and it is unlikely to be surpassed in our generation. The editors are to be admired for having devoted a large portion of their working lives to the project, and Cambridge University Press are to be congratulated on undertaking such a gargantuan publishing task and for the high standards of production. The complete set of five volumes now costs in excess of $£ 150$, but this is a wise investment for any serious botanist, amateur or professional, who wishes to be fully informed about the wealth of Europe's flora.

The development of the Flora Europaea project has not been an isolated process. Floras covering adjacent regions of southwest Asia are proceeding apace. Within the Soviet Union, Flora Europaea covers the entire area west of the Ural Mountains, to $60^{\circ} \mathrm{E}$, and on the southern side of the Black Sea P.H. Davis' work Flora of Turkey and 